\title{
Short communication: Molecular characterization and antimicrobial resistance of pathogenic Escherichia coli isolated from raw milk and Minas Frescal cheeses in Brazil
}

\author{
J. C. Ribeiro Júnior, ${ }^{1 *}$ ๑ F. F. Silva, ${ }^{2} \odot$ J. B. A. Lima, ${ }^{3}$ E. H. Ossugui, ${ }^{2}$ P. I. Teider Junior, ${ }^{2}$ A. C. L. P. Campos, ${ }^{2}$ \\ A. Navarro, ${ }^{4}$ R. Tamanini, ${ }^{2}$ J. Ribeiro, ${ }^{2}$ A. A. Alfieri, ${ }^{2}{ }^{\circ}$ and V. Beloti ${ }^{2}$ \\ ${ }^{1}$ School of Veterinary Medicine and Animal Science, Federal University of Tocantins, Araguaína, Tocantins 77805-2018, Brazil \\ ${ }^{2}$ National Institute of Science and Technology for the Dairy Production Chain (INCT-Leite), State University of Londrina, Londrina, \\ Paraná 86057-970, Brazil \\ ${ }^{3}$ Federal Institute of Maranhão, Microbiology Laboratory, Caxias, Maranhão 65075-441, Brazil \\ ${ }^{4}$ Faculty of Medicine, Department of Public Health, National Autonomous University of Mexico, Ciudad Universitaria, Mexico City 4510, 4513, \\ Mexico
}

\section{ABSTRACT}

The aim of this study was to quantify, identify, evaluate antimicrobial resistance, and characterize the virulence factors of enteropathogenic (EPEC), Shigatoxigenic (STEC), and enterohemorrhagic (EHEC) Escherichia coli in raw milk (RM) and legal (LMFC) and illegal (IMFC) Minas Frescal cheeses in southern and northeast Brazil. Illegal cheeses are those made without official inspection service or sanitary surveillance. We evaluated samples of RM produced in Paraná (southern) and Maranhão (northeast) States, LMFC produced using pasteurized milk in inspected industries, and IMFC potentially produced with raw milk. Mean total coliform counts were $8.4 \times 10^{4} \mathrm{cfu} / \mathrm{mL}$ for $\mathrm{RM}, 1.4 \times 10^{7} \mathrm{cfu} / \mathrm{mL}$ for LMFC, and $2.9 \times 10^{7} \mathrm{cfu} /$ $\mathrm{mL}$ for IMFC. Mean E. coli counts were $2.4 \times 10^{3} \mathrm{cfu} /$ $\mathrm{mL}$ for RM, $1.9 \times 10^{2} \mathrm{cfu} / \mathrm{mL}$ for LMFC, and $1.1 \times 10^{5}$ $\mathrm{cfu} / \mathrm{mL}$ for IMFC. Among the $205 \mathrm{E}$. coli isolates from RM, $9.75 \%$ were identified as EPEC, mainly (90\%) in samples from Paraná. Of the total isolates from the cheese samples, $97.4 \%(\mathrm{n}=111)$ came from IMFC, of which 1.8 and $2.7 \%$ were identified as EPEC and STEC, respectively; no EHEC was detected. The phylogenetic group A (60\%) and typical EPEC (68\%) predominated, which confirms the possible human origin of pathogenic isolates in RM and IMFC. Of these, $50 \%$ were resistant to at least one antibiotic, and streptomycin was the antimicrobial with the highest number (8) of EPEC and STEC resistant isolates. This study reports the first isolation of serogroup O28ac in Brazilian milk. We found no predominance of a specific serogroup of EPEC or STEC in milk or cheese or clonal isolates in the same

Received April 2, 2019.

Accepted July 16, 2019

*Corresponding author: jcribeiro@uft.edu.br sample, indicating different origins of the contamination in these products, presumably mostly related to poor hygienic handling.

Key words: coliforms, enteropathogenic Escherichia coli (EPEC), food safety, Shiga-toxigenic Escherichia coli (STEC)

\section{Short Communication}

Brazil is a large country and significant differences exist in milk quality in different regions of the country (Nero et al., 2005; Ribeiro Júnior et al., 2015). Brazilian small producers, to increase their profitability, often produce dairy products such as Minas Frescal cheese, mostly made with raw milk, and market it illegally. The illegality of these products is associated with the lack of official inspection service and sanitary surveillance. Minas Frescal is one of the most consumed in Brazil and, because it is produced and marketed fresh without maturation and is a very high moisture cheese (46 to $55 \%$ ), it offers ideal conditions for the multiplication and maintenance of pathogenic microorganisms (de Campos et al., 2018).

In contrast to the production conditions of small Brazilian producers, some dairy production areas have a smaller number of producers that produce large volumes of milk using high quality, improved animals and advanced technology (Ribeiro Júnior et al., 2015, 2018).

Among the thermotolerant coliforms (Citrobacter, Enterobacter, Klebsiella, and Escherichia), Escherichia coli is the only microorganism that indicates fecal contamination when present in milk or milk products (Altalhi and Hassan, 2009). Strains of this species may be commensal or pathogenic to the consumer (Kaper et al., 2004; Farrokh et al., 2013; Gomes et al., 2016; Douëllou et al., 2017), and their presence in foods can indicate the presence of other enteropathogens. The 
consumption of raw milk or raw dairy products is still common in Brazil. Thus, pathogenic microorganisms, such as some strains of $E$. coli, in raw milk may pose a risk to public health. These isolates may also be resistant to antibiotics, which hinders hospital treatments (Sáenz et al., 2004).

Considering differences in the quality and conditions of production of raw milk among Brazilian regions, the consumption habits of raw milk or raw milk products, and the potential pathogenicity of strains of E. coli in milk and dairy products, we aimed to quantify total coliforms and E. coli, identify the presence of serotypes with pathogenic potential (i.e., those carrying the eaeA, stx1, stx2, and $b f p A$ genes), and determine the phylogenetic groups and antimicrobial resistance patterns of $E$. coli isolates from refrigerated raw milk produced in 2 regions of Brazil (northeast and south) and Minas Frescal cheeses sold legally and illegally.

In Paraná State in southern Brazil, 70 raw milk (RM) samples were collected from large $(\mathrm{n}=20)$ and small producers $(\mathrm{n}=50)$. In Maranhão State, in northeastern Brazil, 10 samples of refrigerated RM were collected from small farms. All of these dairy farms were previously characterized (Ribeiro Júnior et al., 2015, 2018).

The samples were collected aseptically from storage tanks of raw milk and transported under refrigeration to the National Institute of Science and Technology for the Milk Productive Chain at the State University of Londrina (UEL; Londrina, Paraná, Brazil) or sent to the Microbiology Laboratory of the Federal Institute of Maranhão, Caxias campus (Maranhão, Brazil), where they were immediately processed.

Serial dilutions of milk samples were performed in saline $(0.9 \%)$ peptone $(0.001 \%)$ and with selected samples plated on Petrifilm EC (3M Microbiology, St. Paul, MN) and incubated at $35^{\circ} \mathrm{C}$ for counting total coliforms (TC; $24 \mathrm{~h})$ and E. coli $(48 \mathrm{~h})$ according to the manufacturer's recommendations. The results of the counts were submitted to nonparametric statistical analyses by $\chi^{2}$ test using SAS software (v. 9.0; SAS Institute Inc., Cary, NC).

Ten illegal Minas Frescal cheeses (IMFC), potentially produced with raw milk, were collected from markets in the city of Londrina, Paraná State. Another 10 samples of legally produced Minas Frescal cheese (LMFC) were collected from supermarkets; these cheeses were produced with pasteurized milk, refrigerated, and inspected.

Aliquots $(25 \pm 0.2 \mathrm{~g})$ of each cheese sample were diluted in $225 \mathrm{~mL}$ of $0.1 \%$ buffered saline (Oxoid, Basingstoke, UK), followed by homogenization and serial decimal dilution. The counts of TC and E. coli of the cheese samples were performed in the same way as the milk samples.
All isolates identified as E. coli in Petrifilm EC plates were recovered in brain heart infusion broth (Acumedia, Baltimore, MD) and submitted to genomic DNA extraction by simple boiling (Ribeiro Júnior et al., 2016). The extracts ( $\sim 50 \mathrm{ng})$ were subjected to amplification of the eaeA gene to identify enteropathogenic E. coli (EPEC) and of the stx1 and stx2 genes to verify the production potential of Shiga-like toxins (STEC) according to the primers and reaction conditions described by Paton and Paton (1998), using individual assays for each gene. The presence of enterohemorrhagic $E$. coli (EHEC) was therefore investigated by the simultaneous presence of eaeA and stx1 or stx2 genes.

Isolates identified as EPEC were subjected to new PCR to verify the presence of the $b f p A$ gene (localized adherence) using primers and reaction conditions described by Aranda et al. (2004) for differentiation typical enteropathogenic E. coli (t-EPEC) and atypical (a-EPEC).

The phylogenetic groups of the EPEC or STEC isolates were determined using multiplex PCR described by Clermont et al. (2013). The serotypes of the isolates were identified using the VITEK system (bioMérieux Inc., Durham, NC) and typed with rabbit sera against 56 somatic and flagellar E. coli antigens (Orskov and Orskov, 1984; Scheutz et al., 2004) obtained from the Department of Public Health, Faculty of Medicine, National Autonomous University of Mexico (Ciudad Universitaria, Mexico City).

Antimicrobial resistance was determined using the agar disk diffusion method as recommended by the Clinical and Laboratory Standards Institute (CLSI, 2016) for E. coli. The following antimicrobial agents were used on E. coli samples: amoxicillin-clavulanic acid $(30 \mu \mathrm{g})$, aztreonam $(30 \mu \mathrm{g})$, tetracycline $(30 \mu \mathrm{g})$, cefotaxime $(30 \mu \mathrm{g})$, cefoxitin $(30 \mu \mathrm{g})$, nalidixic acid (30 $\mu \mathrm{g})$, gentamicin $(10 \mu \mathrm{g})$, chloramphenicol $(30 \mu \mathrm{g})$, ampicillin $(10 \mu \mathrm{g})$, ciprofloxacin $(5 \mu \mathrm{g})$, and streptomycin $(10 \mu \mathrm{g})$. Enrofloxacin $(5 \mu \mathrm{g})$ was also tested because this antimicrobial is commonly used in Brazilian veterinary practice. Escherichia coli strain ATCC 25922 was used for quality control.

Extended-spectrum $\beta$-lactamase (ESBL)-producing $E$. coli were confirmed by using the double disk diffusion testing for amoxicillin-clavulanic acid and cefotaxime or ceftazidime, or by using a combination disk test with cefotaxime, cefotaxime-clavulanic acid (Becton Dickinson, Sparks, MD), ceftazidime, and ceftazidime-clavulanic acid (Becton Dickinson), according to Clinical and Laboratory Standards Institute (CLSI) recommendations.

The TC and E. coli counts for RM, IMFC, and LMFC samples are described in Table 1. Considering the TC and E. coli counts of the RM samples evalu- 
Table 1. Total coliform (TC) and Escherichia coli (EC) counts in refrigerated raw milk produced in the states of Paraná and Maranhão and in legal (LMFC) and illegal (IMFC) Minas Frescal cheeses sold in the city of Londrina, Paraná, Brazil

\begin{tabular}{|c|c|c|c|}
\hline Sample & $\mathrm{n}$ & TC $(\mathrm{cfu} / \mathrm{mL})$ & $\mathrm{EC}(\mathrm{cfu} / \mathrm{mL})$ \\
\hline Raw milk & \multirow[t]{4}{*}{80} & & \\
\hline Maximum & & $2.4 \times 10^{6}$ & $1.5 \times 10^{5}$ \\
\hline Minimum & & $<1$ & $<1$ \\
\hline Mean (SD) & & $8.4( \pm 3.3) \times 10^{4}$ & $2.4( \pm 16) \times 10^{3}$ \\
\hline IMFC & \multirow[t]{4}{*}{10} & & \\
\hline Maximum & & $1.4 \times 10^{8}$ & $4 \times 10^{5}$ \\
\hline Minimum & & $<10^{3}$ & $<10^{2}$ \\
\hline Mean (SD) & & $2.9( \pm 4.6) \times 10^{7}$ & $1.1( \pm 1.6) \times 10^{5}$ \\
\hline LMFC & \multirow{4}{*}{10} & & \\
\hline Maximum & & $7.8 \times 10^{7}$ & $10^{3}$ \\
\hline Minimum & & $10^{2}$ & $<10^{2}$ \\
\hline Mean (SD) & & $1.4( \pm 2.3) \times 10^{7}$ & $1.9( \pm 2.8) \times 10^{2}$ \\
\hline
\end{tabular}

ated, only $2.9 \%$ of the total coliforms were E. coli. Of the $80 \mathrm{RM}$ samples, 30 had E. coli isolates, indicating direct or indirect fecal contamination in $37.5 \%$ of the total samples.

Regarding cheese samples, no significant variations $(P>0.05)$ were observed between $\mathrm{TC}$ and $E$. coli counts between LMFC and IMFC, although the counts were considerably lower in LMFC samples. We observed that the average $E$. coli count corresponded to $0.37 \%$ of the mean observed for TC for IMFC and $0.0013 \%$ for LMFC.

From the Petrifilm EC plates used in the counts, 205 E. coli strains were isolated from the milk samples: $34(16.6 \%)$ from RM samples of the large producers, $60(29.3 \%)$ from RM samples of small producers of Paraná, and 111 (51.1\%) strains from milk samples of Maranhão producers. From the cheese samples, colony recovery was proportional to the $E$. coli counts, with 3 isolates from $10 \mathrm{LMFC}$ and 111 from $10 \mathrm{IMFC}$, totaling 114 isolates.

All 319 E. coli isolates were submitted to uniplex PCR to detect the stx1, stx2, and eaeA genes, totaling 957 reactions. The results are shown in Table 2. No single strain from RM samples was positive for the presence of the stx1 or stx2 genes; therefore, no milk sample evaluated by the present study contained STEC. However, $20(9.75 \%)$ of the total RM isolates were positive for EPEC. Of these, 18 (90\%) were isolated from producers in Paraná State and 2 (10\%) from milk sampled in Maranhão State (Table 2). Considering the total of $E$. coli isolates in each production region, EPEC strains represented $19.15 \%$ of the $E$. coli in milk from producers in Paraná and $1.8 \%$ of the isolates of the milk in Maranhão. Thus, regardless of the Brazilian region of production, raw milk is at risk of being contaminated with EPEC, and milk produced in southern Brazil is more likely to be contaminated.
Regarding cheese samples, $2(1.8 \%)$ EPEC strains (strains EC11 and EC12) originated from 2 distinct samples of IMFC and 3 other STEC strains (strains $\mathrm{EC} 13^{\mathrm{a}-\mathrm{c}}$ ) were isolated from the same sample of IMFC. The cheeses legally produced and marketed did not carry any strains of EPEC or STEC, mainly because they were produced with pasteurized milk. Of the strains that tested positive for the eaeA or stx2 genes, none were positive for the 2 genes simultaneously, so no isolates were characterized as EHEC (Table 2).

The $b f p A$ gene was detected (t-EPEC) in $14(70 \%)$ and $1(50 \%)$ of the EPEC isolates from raw milk and cheese samples, respectively (Table 2). Typical and atypical EPEC strains differ primarily in relation to their natural hosts. Humans are the only reservoir of t-EPEC, which are more involved in outbreaks of diarrhea in developing countries, whereas a-EPEC have animal and human reservoirs and are more involved in outbreaks in developed countries (Nataro and Kaper, 1998; Chen and Frankel, 2005; Gomes et al., 2016).

Of the 22 EPEC isolates from RM or IFMC, 9 (40.1\%) were resistant to at least one of the antibiotics tested. Among them, streptomycin had the most resistant strains $(n=8)$ originating from samples and belonging to serogroups and distinct phylogenetic groups (Table 2); ESBL strains were not identified among the 24 EPEC and STEC isolates.

Among the 3 STEC isolates from an IFMC sample, the $\mathrm{EC} 13^{\mathrm{a}}$ isolate was resistant to 3 antibiotics (ampicillin, tetracycline, and streptomycin). The $\mathrm{EC} 13^{\mathrm{c}}$ strain was a STEC of the serogroup OR:H- that was resistant to tetracycline. These 2 strains, however, belong to distinct phylogenetic groups (B2 and A, respectively), indicating that they were not clones within the same cheese sample, as well as the third STEC isolate from the same cheese sample $\left(\mathrm{EC} 13^{\mathrm{b}}\right)$, of serogroup O1:H8 and phylogenetic group B1, which was sensitive to all the antibiotics tested.

Tamaki et al. (2005) correlated serogroup O28ac with enteroinvasive Escherichia coli (EIEC); however, the $i p a H$ gene was not tested in this study. This study is the first to report the O28ac serogroup in Brazilian milk samples.

As large producers control and manage cases of mastitis more closely in their dairy herds, there is greater pressure for the selection of resistant strains on these farms. This study demonstrated that $60 \%$ of the EPEC isolates in milk from large producers were resistant to at least one antibiotic, whereas only $26.6 \%$ of the EPEC isolates from the milk from small producers were resistant.

Phylogenetic group A represented $63.6 \%(14 / 22)$ of EPEC isolates from milk and cheese samples. Carlos et al. (2010) concluded that phylogenetic group A is more 
Table 2. Serotypes, virulence factors, antimicrobial resistance, and phylogenetic groups of pathogenic strains of Escherichia coli isolated from raw milk samples from large and small producers in 2 regions of Brazil and illegal Minas Frescal cheeses

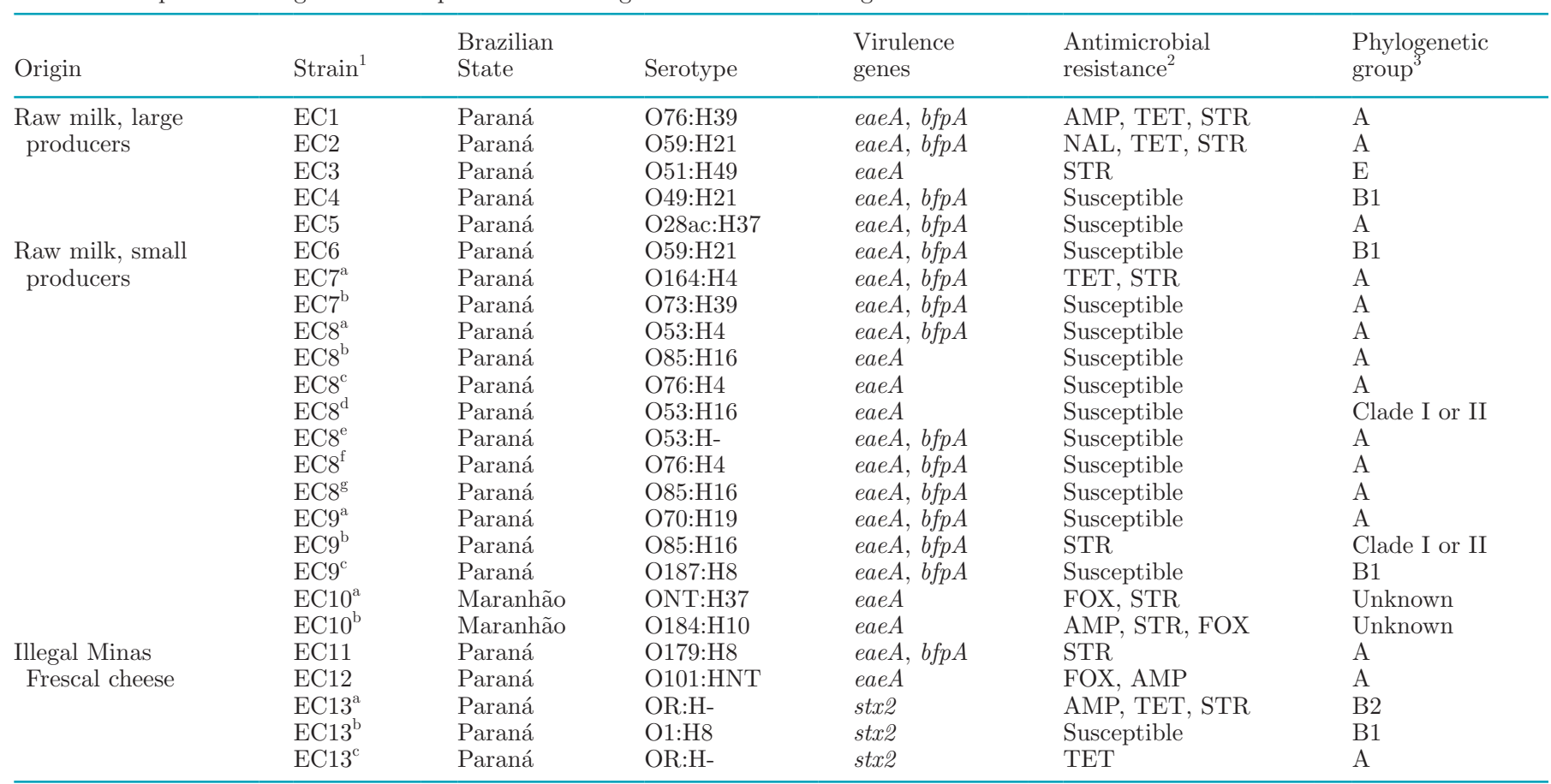

${ }^{1}$ Superscript letters denote strains obtained from the same sample.

${ }^{2} \mathrm{AMP}=$ ampicillin; TET $=$ tetracycline; $\mathrm{STR}=$ streptomycin; NAL $=$ nalidixic acid; FOX $=$ cefoxitin.

${ }^{3}$ According to Clermont et al. (2013).

related to humans, which agrees with the predominance of t-EPEC in the present study (Table 2).

The STEC found in the IFMC samples $\left(\mathrm{EC} 13^{\mathrm{a}-\mathrm{c}}\right)$ belonged to the phylogenetic groups $\mathrm{B} 1, \mathrm{~B} 2$, and $\mathrm{A}$, whose hosts are more related to bovines (B1) and humans (B2 and A; Carlos et al., 2010). Thus, the contamination of milk or cheeses by STEC, as well as by t-EPEC, probably originated in the cheese makers due to hygiene deficiencies.

Brazilian raw milk, regardless of the conditions and region of its production, contains pathogenic E. coli strains, some of which may have antimicrobial resistance. Minas Frescal-type cheeses produced from raw milk pose the same risk, whereas cheeses made with pasteurized milk do not present any risk from pathogenic E. coli isolates. Consumption of Brazilian raw milk or dairy products should be avoided.

\section{ACKNOWLEDGMENTS}

This study was supported by the following Brazilian institutes: the National Council of Scientific and Technological Development (CNPq, Brasília, Brazil; grant no. 305062/2015-8), the Brazilian Federal Agency for Support and Evaluation of Graduate Education (CAPES, Brasília, Brazil; process 88887.145705/2017-
00), the Financing of Studies and Projects (FINEP), and the Araucaria Foundation (FAP/PR, Curitiba, Paraná, Brazil). We thank Marcelo M. Seneda (State University of Londrina, Animal Health Department, Londrina, Paraná, Brazil) for collaboration in the revision of the text, and Tereza C. R. de Oliveira, Renata K. T. Kobayashi, and Gerson Nakazato (State University of Londrina) for methodological assistance.

\section{REFERENCES}

Altalhi, A. D., and S. A. Hassan. 2009. Bacterial quality of raw milk investigated by Escherichia coli and isolates analysis for specific virulence-gene markers. Food Control 20:913-917. https://doi.org/ 10.1016/j.foodcont.2009.01.005.

Aranda, K. R. S., U. Fagundes-Neto, and I. C. A. Scaletsky. 2004 Evaluation of multiplex PCRs for diagnosis of infection with diarrheagenic Escherichia coli and Shigella spp. J. Clin. Microbiol. 42:5849-5853. https://doi.org/10.1128/JCM.42.12.5849-5853 .2004 .

Carlos, C., M. M. Pires, N. C. Stoppe, E. M. Hachich, M. I. Sato, T. A. Gomes, L. A. Amaral, and L. M. Ottoboni. 2010. Escherichia col phylogenetic group determination and its application in the identification of the major animal source of fecal contamination. BMC Microbiol. 10:161-171. https://doi.org/10.1186/1471-2180-10-161.

Chen, H. D., and G. Frankel. 2005. Enteropathogenic Escherichia coli: unravelling pathogenesis. FEMS Microbiol. Rev. 29:83-98. https:/ /doi.org/10.1016/j.femsre.2004.07.002.

Clermont, O., J. K. Christenson, E. Denamur, and D. M. Gordon. 2013. The Clermont Escherichia coli phylo-typing method revisit- 
ed: improvement of specificity and detection of new phylo-groups. Environ. Microbiol. Rep. 5:58-65.

Clinical and Laboratory Standards Institute (CLSI). 2016. Performance Standards for Antimicrobial Susceptibility Testing; 21st Informational Supplement. CLSI document M100-S21. CLSI, Wayne, PA.

de Campos, A. C., J. J. Puño-Sarmiento, L. P. Medeiros, L. E. Gazal, R. P. Maluta, A. Navarro, R. T. K. Kobayashi, E. P. Fagan, and G. Nakazato. 2018. Virulence genes and antimicrobial resistance in Escherichia coli from cheese made from unpasteurized milk in Brazil. Foodborne Pathog. Dis. 15:94-100. https://doi.org/10.1089/ fpd.2017.2345.

Douëllou, T., S. Delannoy, S. Ganet, P. Fach, E. Loukiadis, M. C Montel, and D. Sergentet-Thevenot. 2017. Molecular characterization of O157:H7, O26:H11 and O103:H2 Shiga toxin-producing Escherichia coli isolated from dairy products. Int. J. Food Microbiol. 253:59-65. https://doi.org/10.1016/j.ijfoodmicro.2017.04.010.

Farrokh, C., K. Jordan, F. Auvray, S. Raynaud, D. Thevenot, R Condron, K. De Reu, A. Govaris, K. Heggum, M. Heyndrickx, J. Hummeriohann, D. Lindsay, S. Miszczycha, S. Moussiegt, K. Verstraete, and O. Cerf. 2013. Review of Shiga-toxin-producing Escherichia coli (STEC) and their significance in dairy production. Int. J. Food Microbiol. 162:190-212. https://doi.org/10.1016/j .ijfoodmicro.2012.08.008

Gomes, T. A., W. P. Elias, I. C. Scaletsky, B. E. C. Guth, J. F. Rodrigues, R. M. F. Piazza, L. C. L. Ferreira, and M. B. Martinez. 2016. Diarrheagenic Escherichia coli. Braz. J. Microbiol. 47:3-30. https://doi.org/10.1016/j.bjm.2016.10.015.

Kaper, J. B., J. P. Nataro, and H. L. T. Mobley. 2004. Pathogenic Escherichia coli. Nat. Rev. Microbiol. 2:123-140. https://doi.org/ 10.1038/nrmicro818.

Nataro, J. P., and J. B. Kaper. 1998. Diarrheagenic Escherichia coli. Clin. Microbiol. Rev. 11:142-201. https://doi.org/10.1128/CMR .11.1.142.

Nero, L. A., M. D. Mattos, V. Beloti, M. A. F. Barros, J. P. A. N. Pinto, N. J. Andrade, W. P. Silva, and B. D. G. M. Franco. 2005. Leite cru de quatro regiões leiteiras brasileiras: Perspectivas de atendimento dos requisitos microbiológicos estabelecidos pela Instrução Normativa 51. Cienc. Tecn. Alim. 25:191-195. https://doi .org/10.1590/S0101-20612005000100031.

Orskov, F., and I. Orskov. 1984. Serotyping of Escherichia coli. Methods Microbiol. 14:43-112. https://doi.org/10.1016/S0580 -9517(08)70447-1.
Paton, A. W., and J. C. Paton. 1998. Detection and characterization of Shiga toxigenic Escherichia coli by using multiplex PCR assays for $s t x_{1}, s t x_{2}$, eaeA, enterohemorrhagic $E$. coli hlyA, rfb $b_{\mathrm{O} 111}$, and $r f b_{\mathrm{O} 157}$. J. Clin. Microbiol. 36:598-602.

Ribeiro Júnior, J. C., A. M. Oliveira, F. G. Silva, R. Tamanini, A. L. M. Oliveira, and V. Beloti. 2018. The main spoilage related psychrotrophic bacteria in refrigerated raw milk. J. Dairy Sci. 101:75-83. https://doi.org/10.3168/jds.2017-13069.

Ribeiro Júnior, J. C., R. Tamanini, L. C. C. da Silva, and V. Beloti 2015. Quality of milk produced by small and large dairy producers. Semin. Cienc. Agrar. 36:883-888. https://doi.org/10.5433/ 1679-0359.2015v36n2p883.

Ribeiro Júnior, J. C., R. Tamanini, B. F. Soares, A. M. de Oliveira F. G. Silva, F. F. da Silva, N. A. Augusto, and V. Beloti. 2016 Efficiency of boiling and four other methods for genomic DNA extraction of deteriorating spore-forming bacteria from milk. Semin. Cienc. Agrar. 37:3069-3078. https://doi.org/10.5433/1679-0359 .2016v37n5p3069.

Sáenz, Y., L. Briñas, E. Domínguez, J. Ruiz, M. Zarazaga, J. Vila, and C. Torres. 2004. Mechanisms of resistance in multiple-antibiotic-resistant Escherichia coli strains of human, animal, and food origins. Antimicrob. Agents Chemother. 48:3996-4001. https://doi .org/10.1128/AAC.48.10.3996-4001.2004.

Scheutz, F., T. Cheasty, D. Woodward, and H. R. Smith. 2004. Designation of O174 and O175 to temporary $\mathrm{O}$ groups OX3 and OX7, and six new $E$. coli $\mathrm{O}$ groups that include verocytotoxin producing E. coli (VTEC): O176, O177, O178, O179, O180 and O181. APMIS 112:569-584. https://doi.org/10.1111/j.1600-0463.2004 .apm1120903.X.

Tamaki, Y., H. Narimatsu, T. Miyazato, N. Nakasone, N. Higa, C. Toma, and M. Iwanaga. 2005. The relationship between O-antigens and pathogenic genes of diarrhea-associated Escherichia coli. Jpn. J. Infect. Dis. 58:65-69.

\section{ORCIDS}

J. C. Ribeiro Júnior () https://orcid.org/0000-0002-3272-4375

F. F. Silva @ https://orcid.org/0000-0002-0149-0107

A. A. Alfieri (ㄴ) https://orcid.org/0000-0002-7024-4487 